\title{
ANALISIS KUALITAS MAKANAN PADA SAAT BREAKFASTDI THE ALIGA HOTEL PADANG
}

\author{
Ivony Tresia Adha ${ }^{1}$, Kasmia ${ }^{2}$ \\ Program Studi D4 Manajemen Perhotelan \\ FPP Universitas Negeri Padang \\ email: ivonytresia1234@gmail.com
}

\begin{abstract}
This study originated from the results of previous studies where there were problems regarding the process of managing the procurement of perishable goods that did not have written procedures, the quality requirements of the material written and standardized in the hotel. To continue the problem where there are still problems related to food quality at breakfast at The Aliga Hotel Padang. This study aims to analyze food quality at breakfast at The Aliga Hotel Padang. This type of study is quantitative descriptive. The population in this study were guests who stayed and breakfast at The Aliga Hotel Padang. The sampling technique used is purposive sampling. The total of samples in this study amounted to 91 people. Data collection techniques were carried out by distributing questionnaires (questionnaires) using the Liker scale that has been tested for validity and reliability. Then the data were analysis through data tabulation and descriptive data using percentages. Based on the research that has been done, the results obtained that the quality of food at breakfast at The Aliga Hotel Padang is in the category of enough with a percentage of $45.05 \%$. It is recommended for other researchers to continue research on the quantity offood.
\end{abstract}

Keywords: Food Quality, Breakfast 


\section{PENDAHULUAN}

Pariwisata adalah aktivitas perjalanan yang dilakukan sementara waktu dari tempat tinggal semula ke daerah tujuan dengan alasan bukan untuk menetap atau mencari nafkah melainkan hanya untuk memenuhi rasa ingin tahu, menghabiskan waktu senggang atau libur dan tujuan-tujuan lainnya (Koen Mayers, 2009).Sektor pariwisata merupakan salah satu sektor yang mendorong pertumbuhan ekonomi suatu negara. Sektor pariwisata Indonesia sendiri diproyeksikan mampu menyumbang produk domestik bruto sebesar 15 persen, 280 triliun untuk devisa negara, 20 juta kunjungan wisatawan mancanegara, 275 juta perjalanan wisatawan nusantara dan menyerap 13 juta tenaga kerja pada 2019. Lebih jauh sektor pariwisata diyakini mampu menciptakan pusatpusat pertumbuhan ekonomi yang lebih tersebar di seluruh dunia. Hal ini dikarenakan Indonesia sendiri merupakan negara yang memiliki potensi wisata yang besar dengan segala kekayaan dan keindahan alamnya, peninggalan sejarahnya, budayanya, dan keramah-tamahan masyarakat Indonesia itu sendiri.

Sumatera Barat memiliki potensi wisata alam dengan keindahan alam dan bentang alam seperti pegunungan, perbukitan, dan pantai, selain itu Sumatera Barat juga memiliki beberapa wisata sejarah seperti bangunan peninggalan pada masa penjajahan dan beberapa museum. Kemudian, Sumatera Barat juga terkenal dengan berbagai budayanya yang khas mulai dari tari tradisional, adat istiadat, makanan khas, dan sebagainya. Hal ini tentunya dapat menarik wisatawan untuk mengunjungi Sumatera Barat, khususnya Kota Padang sebagai ibu kota Sumatera Barat. Oleh karena itu, tentunya dibutuhkan komoditas pendukung kepariwisataan di Kota Padang, salah satunya adalah akomodasi sebagai tempat tinggal sementara bagi wisatawan yang berasal dari luar kota maupun mancanegara. Salah satu akomodasi pilihan wisatawan yaitu hotel Menurut Sulastiyono (2011: 5), "Hotel adalah suatu perusahaan yang dikelola oleh pemiliknya dengan menyediakan pelayanan makanan, minuman, dan fasilitas kamar untuk tidur kepada orang-orang yang melakukan perjalanan dan mampu membayar dengan jumlah yang wajar sesuai dengan pelayanan yang diterima tanpa adanya perjanjian khusus".

Industri hotel di Kota Padang telah mengalami peningkatan yang dapat dilihat dari jumlah hotel yang semakin bertambah setiap tahunnya, mulai dari hotel melati, hingga hotel berbintang 3 dan 4 yang menawarkan berbagai fasilitas yang menarik bagi wisatawan untuk menginap. Salah satu hotel berbintang 3 yang menjadi tempat menginap bagi wisatawan yang berkunjung ke Kota Padang adalah The Aliga Hotel Padang. The Aliga Hotel Padang yang berlokasi di jalan $\mathrm{MH}$. Thamrin N0. 17, Padang Selatan, Padang, Sumatera Barat, merupakan 
hotel incaran bagi wisatawan yang berkunjung ke Kota Padang. Hotel ini menyediakan berbagai fasilitas yang mendukung kelancaran dan kenyamanan tamu yang menginap di hotel, baik itu dari fasilitas kamar, fasilitas makanan dan minuman, serta fasilitas umum yang dibutuhkan tamu. Hotel ini terdiri dari 8 departmentyaitu front office department, housekeeping department, food and beverage department, engineering department, IT department, sales and marketting department, accounting department, human resource department.

Food and Beverage Product merupakan departemen yang berfungsi sebagai koordinator kegiatan produksi makanan yang disiapkan untuk tamu hotel. Fungsi ini melaksananakan persiapan (pre preparation) di dapur utama untuk kemudian dikirimkan ke dapur restoran. Dengan demikian, dapur restoran hanya tinggal mengolah makanan yang telah disiapkan di dapur utama (Wiyasha: 2010). Bagian food and Beverage Product memiliki bagian dapur atau kitchen untuk mengolah makanan. Pengertian kitchen menurut Sudiara (2001) yaitu, "Kitchen is a room or other spaces (as a wall area of special building) with facilities for cooking". Pengertian tersebut dapat diartikan dengan singkat bahwa dapur adalah suatu ruangan atau tempat khusus yang memiliki perlengkapan dan peralatan untuk mengolah makanan.

Pengertian breakfastmenurut Pratomo dan Estikowati (2017) adalah, "Salah satu produk yang ditawarkan hotel untuk memudahkan pengunjung yang menginap dalam memenuhi kebutuhan untuk makan. Dengan adanya pelaksanaan breakfastdi hotel, penjunjung akan lebih mudah dalam memenuhi kebutuhan pangan". Oleh karena itu, selain kualitas dari kamar tidur selama menginap, breakfast yang disediakan juga perlu diperhatikan guna memberikan kepuasan kepada tamu yang maksimal.

Berdasarkan hasil penelitian terdahulu dalam skripsi Shakinah (2018) di The Aliga Hotel Padang yang berlokasi di Jalan MH. Thamrin No. 71, Padang Selatan, Padang, Sumatera Barat, penulis mengetahui bahwa The Aliga Hotel Padang merupakan hotel bintang tiga yang terdiri atas 8 departemen, yaitu: Front Office, Housekeeping, Accounting, Sales Marketing, Engineering, Human Resources, Food and Beverage Service, dan Food and Beverage Product. Accounting terdiri dari beberapa bagian yang mengelola alat-alat operasional di hotel, adalah purchasing, store \& receiving, dan cost control. Purchasing bertugas dalam pemesanan barang kepada supplier dengan harga termurah dengan kualitas terbaik. Store dan receiving bertugas dalam menerima barang masuk dan menyimpannya di dalam gudang (store). Akan tetapi, di The Aliga Hotel Padang, purchasing, store \& receiving merupakan bagian yang merangkap yang hanya dilakukan oleh satu orang petugas. Selanjutnya, cost sontrol bertugas mengawasi 
barang-barang yang masih tersedia dan yang telah dipergunakan oleh hotel

The Aliga Hotel Padang memiliki prosedur khusus dalam pengadaan barang perishable. Pertama, jadwal pembuatan market list untuk pemesanan barangperishable, yaitu pada hari Selasa dan Jumat. Sebelum membuat market list, pada pagi hari chef akan melakukan pengecekan persediaan barang yang akan diolah berdasarkan Banquet Event Order (BEO) dan keperluan sehari-hari seperti breakfast, lunch, dan dinner. Banquet Event Order yaitu berupa form yang berisi daftar event yang akan diadakan, jumlah tamu, menu yang akan dipersiapkan, dan perkiraan jumlah makanan yang akan dimasak. Pengecekan diperlukan untuk memperkirakan barang yang akan diorder. Selanjutnya, chef membuat market list dengan menggunakan sistem yang berlaku di The Aliga Hotel Padang, yaitu dengan menggunakan Power Pro.

Market list yang telah dibuat chefharus disetujui terlebih dahulu oleh purchasing. Setelah disetujui dan ditandatangani oleh purchasing, maka pihak purchasing akan menyerahkan ML kepada Finance Control (FC) dan General Manager untuk dicek dan ditandatangani. Setelah itu, purchasing bersama dengan chef de party dan steward langsung berangkat ke pasar untuk membeli semua kebutuhan barang perishable.

Setelah proses pengorderan selesei dan barang tiba di hotel, maka dilakukan pengecekan kuantitas dan kualitas barang berdasarkan market listoleh chef bersama dengan receiving. Barang yang diterima harus sesuai dengan Market List yang telah dibuat sebelumnya agar tidak sulit dalam perubahan data dalam sistem dan tidak harus mengulang lagi dalam pembuatan dan permintaan persetujuan department head beserta perhitungan uang yang telah digunakan dalam pembelian barang.

Menurut Cecep Dani Sucipto (2015:103), Pengolahan Makanan adalah serangkaian kegiatan dalam menangani makanan yang dimulai sejak pengadaan bahan makanan sampai penyajian makanan, dalam lima unsur yaitu tempat, orang, peralatan, makanan, metode proses pengolahan makanan

Kualitas berasal dari bahasa Belanda, yaitu qualitiet yang berarti mutu, menurut J. Supranto, (2011) kualitas adalah sebuah kata yang bagi 30 penyedia jasa merupakan sesuatu yang harus dikerjakan dengan baik, aplikasi kualitas sebagai sifat dari penampilan produk atau kinerja merupakan bagian utama strategi perusahaan dalam rangka meraih keunggulan yang berkesinambungan. Adapun arti kualitas secara umum adalah atribut- atribut atau sifat- sifat tertentu pada suatu produk tersebut dan dapat diukur atau dibandingkan dengan patokan yang ada.

Kualitas makanan atau produk yang dihasilkan harus diawasi dengan baik dan benar dengan memperhatikan 
faktor-faktor yang mempengaruhi dalam pengawasan mutu atau kualitas makanan. Adapun faktor-faktor yang mempengaruhi pengawasan kualitas produk atau makanan menurut Prawirosentono (2004), diantaranya : Pengawasan mutu bahan baku, Pengawasan proses produksi, Pengawasan produk jadi, Pengawasan pengepakan atau kemasan.

\section{METODE PENELITIAN}

Berdasarkan masalah dan tujuan yang ingin dicapai jenis penelitian ini adalah penelitian deskriptif kuantitatif. Populasi penelitian ini adalah tamu dengan sebanyak 91 orang. Non probability sampling yang digunakan adalah Purposives Samplingyaitu teknik pengambilan sampel sumber data dengan pertimbangan tertentu. Sampel dari penelitian ini adalah tamu yang sedang menginap di The Aliga Hotel Padang dengan kriteria, tamu yang membeli kamar dengan biaya individu berusia $>20$ tahun.

\section{HASIL PENELITIAN}

1. Hasil Deskripsi Data Variabel Kualitas Makanan

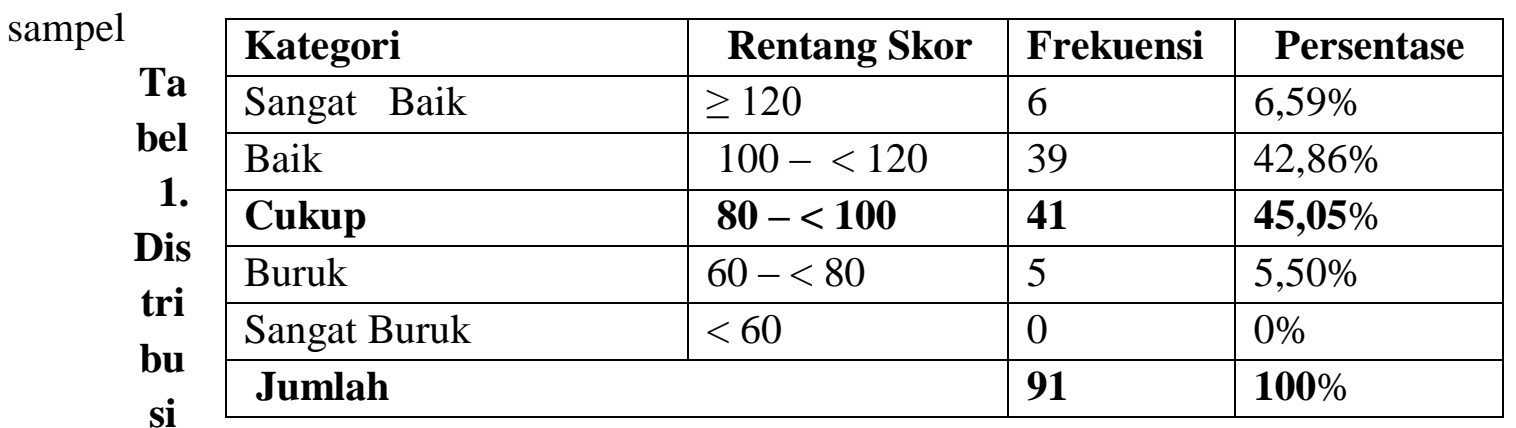

Frekuensi Variabel Kualitas Makanan

Sumber : Data Primer(Diolah), 2018

Berdasarkan tabel diatas dapat dikatakan bahwa kualitas makanan pada saat breakfast di The Aliga Hotel Padang sebanyak $42,86 \%$ responden menyatakan baik kualitas makanannya, 45,05\%responden menyatakan cukup.

2. Hasil Deskripsi Data Variabel Kualitas Makanan Pada Saat 
Tabel 2. Distribusi Frekuensi Indikator Freshnes

\begin{tabular}{|l|l|l|l|}
\hline Kategori & Rentang Skor & Frekuensi & Persentase \\
\hline Sangat Baik & $\geq 60$ & 6 & $6,59 \%$ \\
\hline Baik & $50-<60$ & 42 & $46,15 \%$ \\
\hline Cukup & $40-<50$ & 38 & $41,75 \%$ \\
\hline Buruk & $30-<40$ & 5 & $5,49 \%$ \\
\hline Sangat Buruk & $<30$ & 0 & $0 \%$ \\
\hline \multicolumn{2}{|l|}{ Jumlah } & $\mathbf{9 1}$ & $\mathbf{1 0 0} \%$ \\
\hline
\end{tabular}

Sumber: Data Primer (Diolah), 2018

Berdasarkan tabel di atas

itas makanan breakfast dilihat dapat dikatakan bahwa kualitas makanan pada saat breakfast di dari indikator freshness, sebanyak $5,49 \%$ buruk.

The Aliga Hotel Padang dengan indikator freshness sebanyak $46,15 \%$ responden menyatakan baik dan sebanyak $41,75 \%$ 3. Hasil Deskripsi Data Variabel Kualitas Makanan Pada Saat Breakfast dengan Indikator Presentation responden menyatakan sangat cukup. Namun masih terdapat responden yang menyatakan

\begin{tabular}{|c|c|c|c|c|}
\hline & Kategori & Rentang Skor & Frekuensi & Persentase \\
\hline kual & Sangat Baik & $\geq 19,05$ & 0 & $0 \%$ \\
\hline ab & Baik & $13,35-<16,05$ & 34 & $37,36 \%$ \\
\hline 3 & Cukup & $10,65-<13,35$ & 49 & $53,85 \%$ \\
\hline & Buruk & $7,95-<10,65$ & 8 & $8,80 \%$ \\
\hline & Sangat Buruk & $<7,95$ & 0 & $0 \%$ \\
\hline & \multicolumn{2}{|l|}{ Jumlah } & 91 & $100 \%$ \\
\hline
\end{tabular}

usi

Frekuensi Indikator Presentation 
Sumber : Data Primer (Diolah), 2018

Berdasarkan tabel di atas dapat dikatakan bahwa kualitas makanan pada saat breakfast di The Aliga Hotel Padang dengan indikator presentation sebanyak $37,36 \%$ responden menyatakan baik dan sebanyak 53,85\% responden menyatakan sangat cukup. Namun masih terdapat responden yang menyatakan bahwa kualitas makanan

\begin{tabular}{|c|c|c|c|}
\hline Kategori & Rentang Skor & Frekuensi & Persentase \\
\hline Sangat Baik & $\geq 27$ & 39 & $42,85 \%$ \\
\hline Baik & $25-<27$ & 17 & $18,68 \%$ \\
\hline Cukup & $23-<25$ & 17 & $18,68 \%$ \\
\hline Buruk & $21-<23$ & 10 & $10,99 \%$ \\
\hline Sangat Buruk & $<21$ & 8 & $8,80 \%$ \\
\hline \multicolumn{2}{|l|}{ Jumlah } & 91 & $100 \%$ \\
\hline
\end{tabular}

si Frekuensi Indikator Well Cooked astdilihat dari indikator presentation, sebanyak $8,80 \%$ buruk.

4. Deskripsi Data Variabel Kualitas Makanan Pada Saat Breakfast dengan Indikator Well Cooked

Sumber : Data Primer (Diolah), 2018

Berdasarkan tabel di atas makanan pada saatbreakfast di dapat dikatakan bahwa kualitas The Aliga Hotel Padang dengan 
indikator well cooked sebanyak $18,68 \%$ responden menyatakan baik dan sebanyak $42,85 \%$ responden menyatakan sangat baik. Namun masih terdapat responden yang menyatakan bahwa kualitas makanan breakfastdilihat dari indikator well cooked, sebanyak 10,99\%

\begin{tabular}{|c|c|c|c|}
\hline Kategori & Rentang Skor & Frekuensi & Persentase \\
\hline Sangat Baik & $\geq 12$ & 12 & $13,18 \%$ \\
\hline Baik & $10-<12$ & 42 & $46,15 \%$ \\
\hline Cukup & $8-<10$ & 35 & $38,46 \%$ \\
\hline Buruk & $6-<8$ & 2 & $2,19 \%$ \\
\hline Sangat Buruk & $<6$ & 0 & $0 \%$ \\
\hline \multicolumn{2}{|l|}{ Jumlah } & 91 & $100 \%$ \\
\hline
\end{tabular}

Frekuensi Indikator Variety of Food dan sebanyak 8,80\% responden menyatakan sangat buruk.

5. Hasil Deskripsi Data Variabel Kualitas Makanan Pada Saat Breakfast dengan Indikator Variety of Food
Sumber : Data Primer (Diolah), 2018

Berdasarkan tabel di atas dapat dikatakan bahwa kualitas makanan pada saat breakfast di The Aliga Hotel Padang dengan indikator variety of food sebanyak 38,46\% responden menyatakan cukup dan sebanyak 46,15\% responden menyatakan baik. Namun masih terdapat responden yang menyatakan bahwa kualitas makanan breakfastdilihat dari indikator variety of food, sebanyak $2,19 \%$ buruk.

\section{B. PEMBAHASAN}

Berlandaskan dari hasil penelitian yang sudah peneliti laksanakan, maka diperoleh pembahasan tentang analisis kualitas makanan pada saat breakfast di The Aliga Hotel Padang. Hasil penelitian terhadap 91 orang responden menunjukkan bahwa variabel kualitas makanan pada saat breakfast dapat 
dikategorikan cukup 45,05\% yang artinya breakfast di The Aliga Hotel Padang belum mampu memenuhi harapan tamu. Hal ini sesuai dengan pendapat Knight dan Kotschevar (2000):

"Kualitas makanan adalah tingkat konsistensi kualitas menu yang dicapai dengan penetapan standar untuk produk dan kemudian mengecek point-point yang harus dikontrol untuk melihat kualitas yang ingin dicapai.Jika kualitas makanan tidak memenuhi harapan, tamu tidak puas. Jika kualitas makanan sesuai dengan harapan, tamu puas. Jika kualitas makanan melebihi harapan, tamu sangat puas atau senang".

Kualitas makanan terdiri dari 4 indikator yaitu, freshness, presentation, well cooked, dan variety of food.

1. Kualitas makanan ditinjau dari indikator freshness pada saat tamu breakfast di The Aliga Hotel Padang.

Hasil penelitian mengenai kualitas makanan ditinjau dari indikator freshness pada saat tamu breakfast di The Aliga Hotel Padang dapat dikategorikan baik $46,15 \%$. Artinya kualitas makanan selama breakfast baik. Hal ini dikarenakan tamu yang breakfast di The Aliga Hotel Padang menikmati breakfast sesuai dengan yang diharapkan. Hal ini dapat dibandingkan dengan teori menurut Qin et al (2009) Freshness ialah Kesegaran makanan biasanya diartikan sebagai pernyataan segar dari makanan yang dihubungkan dengan tekstur, rasa, dan aroma dari makanan.

2. Kualitas makanan ditinjau dari indikator presentation pada saat tamubreakfast di The Aliga Hotel Padang.

Hasil penelitian mengenai kualitas makanan ditinjau dari indikator presentation pada saat tamu breakfast di The Aliga Hotel Padang dapat dikategorikan cukup 53,85\%. Artinya kualitas makanan selama breakfast cukup. Kualitas makanan ditinjau dari indikator presentation dapat disimpulkan pada kategori cukup. Hal ini dikarenakan tamu yang breakfast di The Aliga Hotel Padang cukup menikmati breakfast. Hal ini dapat dibandingkan dengan teori menurut Qin et al (2009) presentationadalah Penyajian makanan merupakan suatu cara untuk menyuguhkan makanan kepada konsumen untuk disantap secara keseluruhan yang berisikan komposisi yang telah diatur dan disesuaikan 
dengan permainan warna yang di susun secara menarik agar dapat menambah nafsu makan

3. Kualitas makanan ditinjau dari indikator well cooked pada saat tamu breakfast di The Aliga Hotel Padang.

Hasil penelitian mengenai kualitas makanan ditinjau dari indikator well cooked pada saat tamubreakfast di The Aliga Hotel Padang dapat dikategorikan sangat baik 42,85\%. Artinya kualitas makanan selama breakfast sudah tercapai dengan sangat baik sehingga tamu merasa sangat puas. Hal ini dikarenakan tamu yang breakfast di The Aliga Hotel Padang sangat baik menikmati breakfast. Hal ini dapat dibandingkan dengan teori menurut Qin et al (2009) well cooked adalah Makanan yang akan dihidangkan atau disajikan kepada konsumen hendaknya dimasak atau diolah terlebih dahulu dengan baik dan higienis sehingga aman untuk dikonsumsi oleh konsumen atau pelanggan.

4. Kualitas makanan ditinjau dari indikator variety of food pada saat tamu breakfast di The Aliga Hotel Padang.

$$
\text { Hasil penelitian }
$$
mengenai kualitas makanan ditinjau dari indikator variety of food pada saatbreakfast di The
Aliga Hotel Padang dapat dikategorikan sebagian besar baik $46,15 \%$. Artinya kualitas makanan breakfast sebagian besar sudah tercapai dengan baik. Hal ini dikarenakan tamu yang breakfast di The Aliga Hotel Padang menikmati breakfast sesuai harapan. Namun masih ada yang menyatakan buruk sebanyak 2,19\%. Hal ini dapat dibandingkan dengan teori menurut Qin et al (2009) variety of food adalah Keanekaragaman makanan pada restoran menggambarkan jumlah menu item yang berbeda yang ditawarkan oleh restoran kepada pelanggan atau konsumen.

\section{KESIMPULAN DAN SARAN}

\section{Kesimpulan}

Hasil dari penelitian tentang kualitas makanan saat breakfast di The Aliga Hotel Padang menunjukkan secara total termasuk dalam kategori cukup dengan nilai persentase $45,05 \%$. Berdasarkan penelitian yang penulis lakukan maka dapat diambil kesimpulan sebagai berikut:

a. Kualitas makanan breakfast berdasarkan indicator freshness menyatakan $46,15 \%$ baik.

b. Kualitas makanan breakfast berdasarkan indicator presentation menyatakan 53,85\% cukup. 
c. Kualitas makanan breakfast berdasarkan indicator well cooked menyatakan $42,85 \%$ sanga baik.

d. Kualitas makanan breakfast berdasarkan indicator variety of food menyatakan $46,15 \%$ baik.

\section{Saran}

a. Kepada Pihak Hotel

Kepada manajemen hotel agar selalu memperhatikan kualitas makanan pada saat breakfast di The Aliga Hotel Padang harus lebih ditingkatkan lagi, agar tidak adanya pelanggan yang merasa kurang puas terhadap kualitas makanan, misalnya mengadakan pengawasan dan menerapkan cooking method yang bener, penerapan hygiene dan sanitasi yang menyediakan hand sanitation baik untuk mencuci tangan, menutup makanan yang sudah jadi dan ditaruh di troli, penyimpanan peralatan dan bahan makanan dilakukan dengan pengelompokan sehingga akan terjamin dan hasil yang akan selalu baik dan makanan jadi berkualitas.

b. Kepada Jurusan Pariwisata

Kepada Jurusan Pariwisa ta dan Perhotelan diharapkan penelitian ini dapat menjadi bahan untuk menambah wawasan serta ilmu pengetahuan, serta menjadi informasi yang memadai khususnya bagi pihak terkait dan dapat menjadi bahan pembelajaran.

c. Kepada Peneliti Lain

Bagi peneliti lain yang ingin melaksanakan penelitian tentang kualitas makanan pada saat breakfast, disarankan agar melakukan penelitian tentang kuantitas makanan. Hal ini penting bagi hotel untuk memperhatikan dua produk tersebut demi tercapainya tingkat occoupancy hotel yang tinggi.

DAFTAR PUSTAKA

J Supranto, M.A.,APU. 2011. Pengukuran Tingkat Kepuasan Pelanggan Untuk Menaikkan Pangsa Pasar. Jakarta : PT. Rineka Cipta.

Knight, J.B. and Kotschevar, L.H. 2000.Quantity food Production and Planning.John Willey and Sons.

Pratomo, Virgiawan Ilham, \& Estikowati. (2017). "Pentingnya Variasi Hidangan Breakfst Dalam Meningkatkan Kepuasan Tamu Horison Ultima Malang”. Vol 2 No. 1 Juni 2017.Journal of Universitas Merdeka Malang.

Shakinah, Revani. 2018. "Pengelolaan Pengadaan Barang Perishable di The Aliga Hotel Padang”.Skripsi.Padang: Universitas Negeri Padang. 